\title{
Daily baseline skin care in the prevention, treatment, and supportive care of skin toxicity in oncology patients: recommendations from a multinational expert panel
}

\author{
This article was published in the following Dove Press journal: \\ Cancer Management and Research \\ 6 December 2013 \\ Number of times this article has been viewed
}

\section{René-Jean Bensadoun' \\ Phillipe Humbert ${ }^{2}$ \\ Jean Krutman ${ }^{3}$ \\ Thomas Luger ${ }^{4}$ \\ Raoul Triller ${ }^{5}$ \\ André Rougier 6 \\ Sophie Seite ${ }^{6}$ \\ Brigitte Dreno ${ }^{7}$ \\ 'Department of Radiation Oncology, CHU Poitiers, Poitiers Cedex, 2Department of Dermatology, University Hospital of Besançon, Besançon, France; ${ }^{3}$ IUF-Leibniz Research Institute for Environmental Medicine, Heinrich-Heine University, Düsseldorf, ${ }^{4}$ Department of Dermatology, University of Münster, Münster, Germany; ${ }^{5}$ Centre of Dermatology, Hertford British Hospital, Levallois-Perret, ' ${ }^{6}$ a Roche- Posay Laboratoire Pharmaceutique, Asnières, ${ }^{7}$ Department of Cancero- Dermatology, Hôtel Dieu, CHU Nantes, France}

\begin{abstract}
Skin reactions due to radiotherapy and chemotherapy are a significant problem for an important number of cancer patients. While effective for treating cancer, they disturb cutaneous barrier function, causing a reaction soon after initiation of treatment that impacts patient quality of life. Managing these symptoms with cosmetics and nonpharmaceutical skin care products for camouflage or personal hygiene may be important for increasing patient self-esteem. However, inappropriate product choice or use could worsen side effects. Although recommendations exist for the pharmaceutical treatment of skin reactions, there are no recommendations for the choice or use of dermatologic skin care products for oncology patients. The present guidelines were developed by a board of European experts in dermatology and oncology to provide cancer care professionals with guidance for the appropriate use of non-pharmaceutical, dermocosmetic skin care management of cutaneous toxicities associated with radiotherapy and systemic chemotherapy, including epidermal growth factor inhibitors and monoclonal antibodies. The experts hope that these recommendations will improve the management of cutaneous side effects and hence quality of life for oncology patients.
\end{abstract}

Keywords: skin care, cosmetic, dermatological toxicity, folliculitis, xerosis, chemotherapy, radiotherapy, supportive care, cancer, consensus

\section{Introduction}

Systemic cancer therapy, and radiotherapy, or a combination thereof, has improved the management of many malignancies as well as patient survival rates. However, they are also associated with uncomfortable and disfiguring cutaneous reactions, which continue to be an important issue for both patients and treating physicians..$^{1,2}$ Therefore, preventing and managing these reactions is becoming increasingly important. ${ }^{3}$

Adverse cutaneous reactions associated with radiotherapy or chemotherapeutic agents are comprehensively described in the literature. Hair and nails may be affected, causing alopecia, paronychia, and other abnormalities. Skin barrier function may also be disturbed, resulting in folliculitis (skin rash), xerosis, pruritus, hyperpigmentation, and hand and foot erythema. Additionally, the skin becomes more sensitive to allergens and prone to infection, and becomes more sensitive to ultraviolet radiation. ${ }^{2,4-8}$ The exact mechanisms involved in the pathophysiology are only partly understood. ${ }^{4}$

Radiotherapy causes a variety of side effects, commonly referred to as radiodermatitis. One of the most common acute skin reactions, radiodermatitis can range from mild erythema to severe confluent moist desquamation. All patients
Correspondence: RJ Bensadoun

CHU de Poitiers, BP 577,

8602I, Poitiers, France

Email rene-jean.bensadoun@chu-poitiers.fr 
receiving radiotherapy are at risk of developing these reactions. Therefore, early assessment and management promotes patient comfort and enhances quality of life. ${ }^{9-11}$

Combining radiotherapy and systemic therapy may exacerbate cutaneous reactions, resulting in severe xerosis, inflammation, skin thinning, and necrosis of the upper dermis and epidermis. ${ }^{12}$ Side effects tend to appear early on, and although mostly mild at onset, can become severe and significantly impair quality of life. ${ }^{6}$ These reactions may lead to dose reduction or discontinuation of therapy, which could be detrimental to the outcome of treatment. ${ }^{13}$ Given that disturbances of barrier function are common to all treatments, close and prompt collaboration between oncologists and dermatologists would ensure the best decisions are made for patients, with the objective of managing adverse cutaneous reactions from the start of treatment to minimize therapy changes. ${ }^{14-17}$

Several publications provide recommendations or algorithms for pharmaceutical treatment, but skin care itself remains unclear. ${ }^{3,10,12,18,19}$ Therefore, the authors intend to provide further support for the choice of nonpharmaceutical skin care and cosmetic products for all cancer treatment regimens. This paper is intended to provide oncology health care professionals with recommendations for the most adequate use of nonpharmaceutical skin care products to more effectively prevent and manage skin toxicity and to improve quality of life for cancer patients.

\section{Literature review}

These recommendations are based on an extensive literature review of skin toxicity and use of cosmetics and nonpharmaceutical skin care products adjunctive to current cancer treatments. The authors have focused on skin, mucosal, and nail disorders following oncology treatments as well as on conclusions reached during an expert meeting of six independent European dermatologists and one oncologist held in November 2011. An extensive literature review using PubMed and BIOSIS was performed. Search terms chosen were: "emollient + cancer + skin + quality of life", "sunscreen + cancer + skin", "hygiene + cancer", "make-up + cancer", "radiotherapy + skin toxicity", "standard chemotherapy + skin toxicity", and "targeted therapy + skin toxicity".

During the meeting, the literature concerning different skin toxicities related to targeted chemotherapy and radiotherapy as well as quality of life during oncology therapy was reviewed. Unfortunately, to date, evidence-based support for the adjunctive use of skin care products in oncology therapy remains scarce. Practice is mainly based on anecdotal reports or studies with limited controls. Therefore, the expert group discussed appropriate dermocosmetic skin care products for a certain number of cutaneous reactions, and completed their recommendations with current practice and personal experience.

\section{Definitions}

Dermocosmetic skin care was defined by the expert panel as personal hygiene, cleansing, moisturizing, and photoprotection using nonpharmaceutical or cosmetic products. These products should have been tested clinically in patients with skin diseases and demonstrated a good tolerance profile. Systemic therapy, for the purposes of this paper, refers to key cytotoxic agents such as alkylating agents, antimetabolites, anthracyclines, and topoisomerase inhibitors. Systemic therapy also includes targeted (biologic) therapy or immunotherapy. ${ }^{18,20,21}$ Radiotherapy refers to therapy using high-energy radiation to reduce tumors and destroy cancer cells including X-rays, gamma rays, and charged particles. Supportive care addresses the emotional, physical, and practical issues of cancer, ${ }^{20}$ as opposed to palliative care, defined by the National Cancer Institute as comfort care given to a patient with a serious or life-threatening disease, such as cancer, at diagnosis and throughout the course of illness.

To date, different classifications for degrees of skin toxicity exist. The working group referred to The National Cancer Institute Common Toxicity Criteria version 4, a known and accepted scale for assessment of adverse events. ${ }^{7}$ The expert panel considers that this scale provides objective criteria that enhance the current management of toxicity associated with cancer therapy.

\section{Radiation dermatitis}

Radiation dermatitis may arise in any patient undergoing external beam radiation. It may cause several acute skin reactions including pain, discomfort, irritation, itching, and burning. The majority of clinical trials on supportive care for radiation dermatitis were conducted in patients with brain, breast, head and neck, soft tissue, perineal, and anal canal cancers. A British study demonstrated that dry or moist desquamation was the most common adverse reaction reported after radiation, with $52 \%$ of radiation therapy centers reporting dry desquamation and $85 \%$ reporting moist desquamation as an occasional event.

Skin care during radiotherapy is controversial, given that the assessment and management of adverse reactions differs considerably between institutions and often also between 
individual practitioners. This is possibly due to a lack of evidenced-based studies. ${ }^{20}$

Inconsistent communication between practitioners may lead to patients receiving conflicting or even erroneous information. Areas where opinions differ include use of washing soaps, creams, and deodorants and in the management of dry and moist desquamation, saline soaks, gel or occlusive dressings, and topical antibiotics. Restrictive skin care practices that interfere with normal hygiene can be very distressing for the patient, making them feel socially unacceptable at a time when social support is very important. ${ }^{7}$ Social support from family, friends, and health care professionals is vital for healthy and adaptive adjustment to a cancer diagnosis.

Bolderston et al reported that the risk of dry and moist desquamation should not increase if skin care products are applied between treatments and that there is no significant bolus effect with normal use of such products when using modern megavoltage radiation therapy equipment. ${ }^{8}$ Bernier et al suggest that patients should be encouraged to maintain good hygiene standards and to wash with $\mathrm{pH}$-neutral synthetic cleansers. Nonperfumed moisturizers can be used between treatments. If anti-infective measures are considered appropriate, an emollient containing an antiseptic can be used occasionally. ${ }^{12}$ Kumar et al, in their review of radiation therapy management, also recommend bathing with mild soaps. ${ }^{20}$ The objective when managing dry desquamation is to alleviate discomfort, providing that there is no skin breakdown and no potential for infection. Skin hydration has been recommended to relieve symptoms of dry skin and to reduce further aggravation associated with pruritus that leads to secondary infection. ${ }^{22}$ The opposite is true for moist desquamation, in that the skin breaks down and becomes susceptible to infection, for which antibacterial or antifungal medication is currently prescribed. ${ }^{12}$

\section{Cutaneous effects of systemic chemotherapy Rash}

Rash (folliculitis) is the most common reaction to systemic therapy, occurring in $43 \%-85 \%$ of patients treated with targeted chemotherapy. ${ }^{1,23}$ Rash follows a typical chronologic pattern that peaks in severity during the first 1-2 weeks of treatment. ${ }^{2,24}$ Although it is not associated with death, there have been reports of serious morbidity. ${ }^{19}$ Over-the-counter acne products, including formulations containing benzoyl peroxide and topical retinoids such as tretinoin, adapalene, or tazarotene, have not been shown to be useful because they dry the skin and may cause burning, stinging, and irritation without being beneficial in treating rash. ${ }^{3,5,23}$ Segaert et al suggest using oil-in-water creams and avoiding treatments with vehicles containing alcohol when treating rash. ${ }^{2}$

Grade 1 rash has been successfully managed with emollients and adapted skin cleansers or topical antibiotics and antiseptic soap. ${ }^{19,25}$ In the current absence of consistent clinical trials in subjects with more severe rash, patients are advised to use mild skin care and photoprotection. ${ }^{5}$

Nonocclusive make-up with a high pigment concentration to adequately cover scars and lesions has been consistently recommended to cover grade 1 and 2 rash. ${ }^{3,26}$ Patients should avoid allergenic over-the-counter products. Make-up should be removed with a dermatologist-approved, low-irritant, nonalcohol-based hypoallergenic remover. ${ }^{26,27}$

\section{Xerosis cutis}

Xerosis is a common side effect of systemic therapy, appearing several weeks after treatment in up to $35 \%$ of patients. ${ }^{5,28}$ When aggravated, asteatotic eczema can occur, which can become complicated by secondary Staphylococcus aureus or Herpes simplex infection. Xerosis cutis and subsequent eczema are often correlated with older age and a tendency towards atopy. If dry skin appears on the hands or feet, patients may develop painful toes and fingertips (pulpitis sicca) or fissures on the dorsal sides of the interphalangeal joints. ${ }^{28}$

Some publications recommend educating patients on preventative measures prior to any therapy, including avoiding soaps, limiting shower time, using lukewarm water, and frequent use of emollients. Further, they suggest treating xerosis cutis with standard emollients, such as 5\%-10\% urea in cetomacrogol cream. ${ }^{5,9,29}$ Ointments should be avoided because they may lead to follicular occlusion and folliculitis. Eczema should be treated intermittently with a moderate to potent corticosteroid over several weeks. Pulpitis should be treated with frequently applied emollients, in combination with moderate corticosteroids if needed.

One pilot study of 13 patients found that proactive application of an emollient containing niacinamide reduced the frequency of adverse events and maintained quality of life..$^{30}$ Beyond proactive application of emollients when treating moderate to severe xerosis, one author also suggests switching to topical medication with oil-in-water vehicles, and for the limbs, water-in-oil formulations may be considered. ${ }^{24}$ A more complete approach includes hydration of the stratum corneum associated with prophylactic use of an acidic ( $\mathrm{pH}$ 5.5) skin care system (emollient and cleanser), ie, specifically 
formulated hand and foot emollients, liquid bandages, thick emollients containing 5\%-10\% urea for fissures, and use of antiseptic creams to prevent infection. ${ }^{6,19}$

\section{Skin photosensitivity}

Skin toxicities such as rash and xerosis can be exacerbated by sun exposure. ${ }^{18,31,32}$ The skin becomes more sensitive to ultraviolet radiation, and in certain cases, sunlight can cause pigmentation changes. ${ }^{33,34}$ Symptom management and supportive care forums on dermatologic toxicity management recommend applying a broad-spectrum sunscreen (SPF 15 or higher with a UVA-PF) particularly for lighter skin types and the expected level of induced photosensitivity. ${ }^{9,27}$

\section{Paronychia}

Paronychia is a painful inflammatory reaction of the nail folds. ${ }^{28,36}$ It is difficult to treat and may cause infection. Epidermal growth factor receptor inhibitors often cause paronychia, although the pathogenesis remains speculative. Preventative measures include wearing wide fitting shoes, adequate nail care, hygiene to prevent secondary impetiginization, and use of local antiseptics and antibiotic creams. ,24,26 $^{2,2}$ Nail removal or coagulation of granulation tissue can be considered for very painful nail disorders resistant to therapy. Nail growth is frequently retarded and the nails can become brittle. These nail disorders do not require therapy. Application of nail polish to harden the nails, liquid bandages, and glue has been used to prevent nail fragmentation. ${ }^{28}$

\section{Hand-foot syndrome}

Hand-foot syndrome is the most severe side effect, and is associated with capecitabine and other 5-fluorouracil derivatives in particular. To date, the pathophysiology of hand-foot syndrome has not been fully characterized. Involvement of the epidermis of the palms and soles, accompanied by damage to the epithelial cells of the eccrine ducts, suggests that this syndrome may involve more than a direct toxic effect on basal keratinocytes..$^{37,40}$ Early recognition of hand-foot syndrome toxicity is important because it can progress quickly to higher grades of toxicity with debilitating consequences. ${ }^{38}$ Mild reactions have been treated successfully with urea or salicylic acid ointment. ${ }^{24,25}$ Careful attention should be paid to superficial cuts or scrapes to prevent infection. ${ }^{39}$

\section{Changes in patient quality of life}

The pain and morbidity associated with chemotherapy and radiotherapy can be difficult for patients to bear because skin changes and nail problems are particularly visible. The use of cosmetics may therefore significantly improve self-image and decrease anxiety. ${ }^{15}$ Early education and continued encouragement throughout treatment regarding use of cosmetics and management of side effects contributes significantly to better management of symptoms. ${ }^{40-42}$ Training seminars that teach both men and women appropriate skin care, camouflage, and dressing techniques, have been successful in restoring selfesteem, particularly in those with pre-existing low esteem. ${ }^{43,44}$ Hence, use of adequate cosmetics and appropriate skin care management may definitively improve quality of life.

\section{Currently proposed cosmetics and skin care procedures Expert point of view}

The present point of view focuses on a preventative and supportive skin care approach to assist patients undergoing oncology treatment and their caregivers to choose the most suitable products for daily skin care. Based on the literature and personal experience, the experts consider that all anticancer therapy-related cutaneous adverse events are linked to skin barrier dysfunction. Hence, maintaining skin barrier function using appropriate skin care products may control the severity of these symptoms.

Toxicity arises early after the first treatment, and there is no clear evidence regarding which patients may be susceptible, ${ }^{9,19,24,45}$ although a correlation between older age, atopic predisposition, and a higher incidence of xerosis has been reported. ${ }^{27}$

\section{Cosmetics}

Advising patients regarding choice of the most appropriate cosmetic to be used during and after their cancer treatment is another important issue. A number of cosmetic products are formulated for and clinically tested on fragile, diseased, and sensitive skin, and so may be more appropriate in this patient population.

\section{Skin cleansing}

Skin cleansing advice is important. Many hygiene products can aggravate symptoms. ${ }^{46,47}$ The cleansing process removes both sebum and impurities, thus further drying damaged skin. ${ }^{48}$ This is particularly detrimental to skin affected by chemotherapy and radiotherapy where the skin barrier is already disturbed. ${ }^{10,12,13}$ Without professional guidance, patients tend to experiment with inappropriate self-care products that aggravate the situation and irritate their sensitive skin. ${ }^{15}$ 
Combination of an acidic cleanser and emollient ( $\mathrm{pH}$ 5.5) and use of an antiseptic soap has been reported to improve barrier function, hydration of the stratum corneum, and skin surface lipids. ${ }^{25}$ Use of $\mathrm{pH}$-neutral soaps is preferred. Therefore, washing with appropriate and preferably clinically tested cleansers is recommended.

\section{Skin hydration}

Radiotherapy and chemotherapy reduce the skin's tolerance to cosmetic products, and this has been attributed to an imbalance in the stratum corneum, which ultimately disrupts skin barrier function. ${ }^{13,47}$ Adequate hydration improves barrier function, reduces pruritus, and prevents secondary infection due to scratching. ${ }^{15}$ Emollients repair and protect the epidermal barrier by binding water within the stratum corneum and providing partial surface hydration, and thereby improving epidermal barrier function. This limits the stinging, scaling, redness, and cracks associated with radiotherapy-induced and chemotherapy-induced xerosis. ${ }^{12}$ Thus, skin care with clinically tested moisturizers improves barrier function and skin hydration to manage cutaneous reactions prior to, during, and after oncology therapy.

\begin{tabular}{|c|c|c|}
\hline \multicolumn{2}{|c|}{$\begin{array}{l}\text { Preventative measures } \\
\text { Supportive education }\end{array}$} & Grade 0 \\
\hline$\downarrow$ & $\downarrow$ & \\
\hline \multirow[t]{2}{*}{ Success } & Progression & Grade 1 \\
\hline & $\begin{array}{l}\text { Specific dermocosmetic adjuvant use } \\
\text { Hygiene }+ \text { moisturizer }+ \text { sun protection }+ \text { camouflage }\end{array}$ & \\
\hline$\downarrow$ & $\downarrow$ & \\
\hline \multirow[t]{2}{*}{ Success } & Progression & Grade 2 \\
\hline & $\begin{array}{l}\text { Specific dermocosmetic adjuvant use } \\
\text { Hygiene + moisturizer + sun protection + camouflage + wound repair } \\
+ \text { Topical corticosteroids } \\
\text { + Referral to a dermatologist }\end{array}$ & \\
\hline$\downarrow$ & $\downarrow$ & \\
\hline \multirow[t]{2}{*}{ Success } & Progression & Grade 3 \\
\hline & $\begin{array}{l}\text { Specific dermocosmetic adjuvant treatment } \\
\text { Hygiene + moisturizer + sun protection + camouflage + wound repair } \\
+ \text { Topical corticosteroids } \\
+ \text { Referral to a dermatologist }\end{array}$ & \\
\hline$\downarrow$ & $\downarrow$ & \\
\hline \multirow[t]{2}{*}{ Success } & Progression & Grade 4 \\
\hline & $\begin{array}{l}\text { Specific dermocosmetic adjuvant treatment } \\
\text { Hygiene + moisturizer + sun protection + camouflage + wound repair } \\
+ \text { Systemic therapy } \\
+ \text { Referral to a dermatologist }\end{array}$ & \\
\hline
\end{tabular}

Figure I Proposed algorithm for management of skin adverse events associated with oncology therapies. 


\section{Photoprotection}

Daily photoprotection is important in preventing pigmentation changes occurring as a result of heightened ultraviolet sensitivity. ${ }^{33,34}$ Symptom management and supportive care forums on dermatologic toxicity management recommend applying a broad-spectrum sunscreen (SPF 15 or higher with a UVA-PF) according to phototype and extent of photosensitivity induced. ${ }^{12,26}$

\section{Use of deodorants}

Use of antiperspirants and deodorants is a controversial, given that the effect of chemotherapy on the eccrine glands eliminates the need to use these products. However, the experts feel that in the interests of patient well-being, deodorants and nonirritant perfumes may be used as part of maintaining a daily routine.

\section{General recommendations}

The present recommendations for use of dermocosmetic skin care and cosmetic products are intended to improve the management of cutaneous side effects and enhance quality of life in oncology patients. Patients should receive adequate information about dermocosmetic skin care and cosmetic products as well as education on their appropriate use from the beginning of their oncology treatment. This should be continued and encouraged throughout and after treatment. When symptoms occur, they should be evaluated throughout therapy, and topical or systemic treatments may be added if necessary, according to existing guidelines. Dermatology referral should be considered when symptoms worsen (see Figure 1).
Hence, based on the above discussion, the experts propose the following general recommendations for basic skin care (see Table 1):

1. Continue gentle skin cleansing. Synthetic detergents (syndets), clinically tested and with a $\mathrm{pH}$ of 5.5, are generally well tolerated and suitable for daily use.

2. Apply a noncomedogenic moisturizing cream on both the face and body daily, from the first treatment, irrespective of whether this is chemotherapeutic or radiotherapeutic. Avoid daily application of body lotion during treatment with lipophilic chemotherapeutic agents.

3. Apply broad-spectrum sunscreen to the face and other exposed areas, ie, neck and arms (SPF 15 with a UVA-PF) according to phototype or expected photosensitivity.

\section{Additional recommendations}

1. Consider oil-in-water vehicles for medical treatment and emollients containing humectants such as urea 5\%-10\% or niacinamide.

2. Apply noncomedogenic make-up to cover erythema and mask pallor, and avoid occlusive make-up if folliculitis is severe.

3. Fruit acids, antibacterials, and benzoyl peroxide are not helpful for treating rash, may cause irritation, and can be harmful.

4. Antiseptics and wound healing creams may be helpful in managing fissures and paronychia.

Table I Adjunctive dermocosmetics for the management of skin reactions due to radiation or systemic therapy

\begin{tabular}{|c|c|c|}
\hline Toxic effect & Preventative skin care products & Hazardous skin care products \\
\hline \multirow[t]{4}{*}{ Radiation dermatitis } & Gentle cleansers $^{12,20}$ & - \\
\hline & Photoprotection ${ }^{12}$ & \\
\hline & Apply moisturizers to relieve itching ${ }^{12}$ & \\
\hline & Antibacterial moisturizers ${ }^{12}$ & \\
\hline \multirow[t]{4}{*}{ Rash } & Gentle skin cleansers ${ }^{19}$ & Potentially allergenic products ${ }^{3}$ \\
\hline & Proactive emollient application & Over-the-counter acne treatments: \\
\hline & Photoprotection $18,26,31$ & benzoyl peroxide, tretinoin, \\
\hline & Nonocclusive make-up ${ }^{3,26,27}$ & tazarotene, adapalene $e^{3,25,26}$ \\
\hline \multirow[t]{6}{*}{ Xerosis } & Gentle (pH 5.5) skin cleansers ${ }^{19}$ & Soaps ${ }^{28}$ \\
\hline & Frequent emollient application ${ }^{28}$ & Ointments ${ }^{28}$ \\
\hline & Photoprotection ${ }^{26}$ & \\
\hline & Emollients containing $5 \%-10 \%$ urea $^{28,30}$ & \\
\hline & Antiseptic creams for fissures ${ }^{12,19}$ & \\
\hline & Oil-in-water-vehicle for topical medication ${ }^{24}$ & \\
\hline \multirow[t]{2}{*}{ Paronychia } & Local antiseptics ${ }^{2,26}$ & - \\
\hline & Liquid bandages or glue for nail splitting ${ }^{28}$ & \\
\hline Hand and foot & Urea or salicylic acid ointment ${ }^{2,25}$ & - \\
\hline
\end{tabular}




\section{Acknowledgment}

The authors acknowledge Amy Whereat and Karl Patrick Göritz for their assistance in writing and editing this manuscript.

\section{Disclosure}

This guideline was funded by La Roche-Posay Laboratoire Pharmaceutique, France. All authors except for RJB are members of the scientific advisory board of La Roche-Posay Laboratoire Pharmaceutique, France. SS and AR are employees of La RochePosay Laboratoire Pharmaceutique, France. All members of the expert panel received honoraria for their contribution to this work. The authors report no other conflicts of interest in this work.

\section{References}

1. Robert C, Soria JC, SpatzA, et al. Cutaneous side-effects of kinase inhibitors and blocking antibodies. Lancet Oncol. 2005;6(7):491-500.

2. Segaert S, Chiritescu G, Lemmens L, Dumon K, Van Cutsem E, Tejpar S. Skin toxicities of targeted therapies. Eur J Cancer. 2009;45 Suppl 1: 295-308.

3. Perez-Soler R, Delord JP, Halpern A, et al. HER1/EGFR inhibitorassociated rash: future directions for management and investigation outcomes from the HER1/EGFR inhibitor rash management forum. Oncologist. 2005;10(5):345-356.

4. Lacouture ME, Lai SE. The PRIDE (Papulopustules and/or paronychia, Regulatory abnormalities of hair growth, Itching, and Dryness due to Epidermal growth factor receptor inhibitors) syndrome. Br J Dermatol. 2006;155(4):852-854.

5. Agero AL, Dusza SW, Benvenuto-Andrade C, Busam KJ, Myskowski P, Halpern AC. Dermatologic side effects associated with the epidermal growth factor receptor inhibitors. J Am Acad Dermatol. 2006;55(4): 657-670.

6. Lynch TJ Jr, Kim ES, Eaby B, Garey J, West DP, Lacouture ME. Epidermal growth factor receptor inhibitor-associated cutaneous toxicities: an evolving paradigm in clinical management. Oncologist. 2007;12(5):610-621

7. Campbell J, Lane C. Developing a skin-care protocol in radiotherapy. Prof Nurse. 1996;12(2):105-108.

8. Bolderston A, Lloyd NS, Wong RK, Holden L, Robb-Blenderman L. Supportive Care Guidelines Group of Cancer Care Ontario Program in Evidence-Based Care. The prevention and management of acute skin reactions related to radiation therapy: a systematic review and practice guideline. Support Care Cancer. 2006;14(8):802-817.

9. Peuvrel L, Bachmeyer C, Reguiai Z, et al. Semiology of skin toxicity associated with epidermal growth factor receptor inhibitors. Support Care Cancer. 2102;20(5):909-921.

10. McQuestion M. Evidence-based skin care management in radiation therapy. Semin Oncol Nurs. 2006;22(3):163-173.

11. Reguiai Z, Bachet J, Bachmeyer C. Management of cutaneous adverse events induced by anti-EGFR (epidermal growth factor receptor): a French interdisciplinary therapeutic algorithm. Support Care Cancer. 2012;207:1395-1404.

12. Bernier J, Bonner J, Vermorken J, et al. Consensus guidelines for the management of radiation dermatitis and coexisting acne like rash in patients receiving radiotherapy plus EGFR inhibitors for the treatment of squamous cell carcinoma of the head and neck. Ann Oncol. 2008;19(1): 142-149.

13. Fluhr J, Miteva M, Primavera G, Ziemer M, Elsner P, Berardesca E. Functional assessment of a skin care system in patients on chemotherapy. Skin Pharmacol Physiol. 2007;20(5):253-259.
14. Jatoi A, Nguyen PL. Do patients die from rashes from epidermal growth factor receptor inhibitors? A systematic review to help counsel patients about holding therapy. Oncologist. 2008;13(11):1201-1204.

15. Haley A, Calahan C, Gandhi M, West D, Rademaker A, Lacouture M. Skin care management in cancer patients: an evaluation of quality of life and tolerability. Support Care Cancer. 2011;19(4):545-554.

16. Wacker B, Nagrani T, Weinberg J, Witt K, Clark G, Cagnoni P. Correlation between development of rash and efficacy in patients treated with the epidermal growth factor receptor tyrosine kinase inhibitor erlotinib in two large phase III studies. Clin Cancer Res. 2007;13(13): 3912-3921.

17. Wolf M, Swaisland H, Averbuch S. Development of the novel biologically targeted anticancer agent gefitinib: determining the optimum dose for clinical efficacy. Clin Cancer Res. 2004;10(14):4607-4613.

18. Melowsky B, Burkes R, Rayson D, Alkindor T, Shear N, Lacouture ME. Management of skin rash during EGFR-targeted monoclonal antibody treatment for gastrointestinal malignancies: Canadian recommendations. Curr Oncol. 2009;16(1):17-26.

19. Burtness B, Anadkat M, Basti S, et al. NCCN Task Force Report: Management of dermatologic and other toxicities associated with EGFR inhibition in patients with cancer. $J$ Nat Compr Canc Netw. 2009;7 Suppl 1:S5-S21.

20. Kumar S, Juresic E, Barton M, Shafiq J. Management of skin toxicity during radiation therapy: a review of the evidence. $J$ Med Imaging Radiat Oncol. 2010;54(3):264-279.

21. Noushin H, Haley N, Susan B. Chemotherapeutic agents and the skin: an update. J Am Acad Dermatol. 2008;58:545-570.

22. Maddocks-Jennings W, Wilkinson JM, Shillington D. Novel approaches to radiotherapy-induced skin reactions: A literature review. Complement Ther Clin Pract. 2005:11(4):224-231.

23. Jatoi A, Green EM, Rowland KM Jr, Sargent DJ, Alberts SR. Clinical predictors of severe cetuximab-induced rash: observations from 933 patients enrolled in north central cancer treatment group study N0147. Oncology. 2009;77(2):120-123.

24. Segaert S, Van Cutsem E. Clinical signs, pathophysiology and management of skin toxicity during therapy with epidermal growth factor receptor inhibitors. Ann Oncol. 2005;16(9):1425-1433.

25. Roe E, Garcia Muret MP, Marcuello E, Capdevila J, Pallares C, Alomar A. Description and management of cutaneous side effects during cetuximab or erlotinib treatments: a prospective study of 30 patients. $J$ Am Acad Dermatol. 2006;55(3):429-437.

26. Ouwerkerk J, Boers-Doets C. Best practices in the management of toxicities related to anti-EGFR agents for metastatic colorectal cancer. Eur J Oncol Nurs. 2010;14(4):337-349.

27. Moore S. Managing treatment side effects in advanced breast cancer. Semin Oncol Nurs. 2007;23(4 Supp1 2):S23-S30.

28. Galimont-Collen AF, Vos LE, Lavrijsen AP, Ouwerkerk J, Gelderblom H. Classification and management of skin, hair, nail and mucosal sideeffects of epidermal growth factor receptor (EGFR) inhibitors. Eur $J$ Cancer. 2007;43(5):845-851.

29. Hu JC, Sadeghi P, Pinter-Brown LC, Yashar S, Chiu MW. Cutaneous side effects of epidermal growth factor receptor inhibitors: clinical presentation, pathogenesis, and management. J Am Acad Dermatol. 2007;56(2):317-326.

30. Wohlrab J, Luftner D, Johne A, Camara O, Dominik S, Runnebaum I. The advantage of a proactive, barrier-protective, supportive skin care in patients with brest cancer on chemotherapy. Oncology. 2011; 34(6):62.

31. El-Abaseri T, Hansen L. EGFR activation and ultraviolet light-induced skin carcinogenesis. J Biomed Biotechnol. 2007;2007(3):97939.

32. Jacot W, Bessis D, Jorda E, Ychou M, Fabbro M, Pujol J. Acniform eruption induced by epidermal growth factor receptor inhibitors in patients with solid tumours. Br J Dermatol. 2004;151(1):238-241.

33. Luu M LS, Patel J, Guitart J, Lacouture ME. Photosensitive rash due to the epidermal growth factor receptor inhibitor erlotinib. Photodermatol Photoimmunol Photomed. 2007;23(1):42-45. 
34. Funke A, Kulp-Shorten C, Callen J. Subacute cutaneous lupus erythematosus exacerbated or induced by chemotherapy. Arch Dermatol. 2010;146(10):1113-1116.

35. Perez-Soler R, Saltz L. Cutaneous adverse events with HER1/EGFRtargeted agents: is there a silver lining? J Clin Oncol. 2005;23(22): 5235-5246.

36. Rigopoulos D, Larios G, Gregoriou S, Alevizos A. Acute and chronic paronychia. Am Fam Phys. 2008;77(3):339-346.

37. Rongioletti F, Ballestrero A, Bogliolo F, Rebora A. Necrotizing eccrine squamous syringometaplasia presenting as acral erythema. J Cutan Pathol. 1991;18(6):453-456.

38. Wasif Saif M, Aymen A. Identifying and treating fluoropyridimineassociated hand and foot syndrome in white and non-white patients. J Support Oncol. 2007;5(7):337-343.

39. Scheithauer W, Blum J. Coming to grips with hand-foot syndrome. Insights from clinical trials evaluating capecitabine. Oncology (Williston Park). 2004;18(9):1161-1168.

40. Titeca G, Poot F, Cassart D, et al. Impact of cosmetic care on quality of life in breast cancer patients during chemotherapy and radiology. JEur Acad Dermatol Venereol. 2007;21(6):771-776.

41. Hirsh V. Managing treatment-related adverse events associated with EGFR tyrosine kinase inhibitors in advanced non-small-cell lung cancer. Curr Oncol. 2011;18(3):126-138.
42. Williams S, Schreier A. The effect of education in managing side effects in women receiving chemotherapy for treatment of breast cancer. Oncol Nurs Forum. 2004;31(1):E16-E23.

43. Anderson M, Johnson J. Restoration of body image and self-esteem for women after cancer treatment: a rehabilitative survey. Cancer Pract. 1994;2(5):345-349.

44. Fawzy N, Secher L, Evans S, Giuliano A. The Positive Appearance Center: an innovative concept in comprehensive psychosocial cancer care. Cancer Pract. 1995;3(4):233-238.

45. Boone SL, Rademaker A, Liu D, Pfeiffer C, Mauro DJ, Lacouture ME. Impact and management of skin toxicity associated with antiepidermal growth factor receptor therapy: survey results. Oncology. 2007;72(3-4):152-159.

46. Wolf R, Wolf D, Tüzün B, Tüzün Y. Soaps, shampoos, detergents. Clin Dermatol. 2001;19(4):393-397.

47. Lacouture ME. Mechanisms of cutaneous toxicities to EGFR inhibitors. Nat Rev Cancer. 2006;6(10):803-812.

48. Thune $P$. The effects of detergents on hydration and skin surface lipids. Clin Dermatol. 1996;14(1):29-33.

\section{Publish your work in this journal}

Cancer Management and Research is an international, peer-reviewed open access journal focusing on cancer research and the optimal use of preventative and integrated treatment interventions to achieve improved outcomes, enhanced survival and quality of life for the cancer patient. The journal welcomes original research, clinical \& epidemiological

\section{Dovepress}

studies, reviews \& evaluations, guidelines, expert opinion \& commentary, case reports \& extended reports. The manuscript management system is completely online and includes a very quick and fair peerreview system, which is all easy to use. Visit http://www.dovepress.com/ testimonials.php to read real quotes from published authors. 